INTENSIF, Vol.3 No.1 February 2019

ISSN: 2580-409X (Print) / 2549-6824 (Online)

Website: http://ojs.unpkediri.ac.id/index.php/intensif

\title{
Evaluasi Kualitas Website Program Studi Sistem Informasi Universitas PGRI Madiun Menggunakan Webqual 4.0
}

Website Quality Evaluation of Program Studi Information Systems at Universitas PGRI Madiun Using Webqual 4.0

\author{
${ }^{1}$ Ridho Pamungkas, ${ }^{2}$ Saifullah \\ ${ }^{1,2}$ Sistem Informasi, Universitas PGRI Madiun \\ ${ }^{1,2}$ Madiun, Indonesia \\ E-mail: ${ }^{1}$ ridho.pamungkas@ unipma.ac.id, ${ }^{2}$ saifullah @unipma.ac.id
}

\begin{abstract}
Abstrak-Penelitian ini bertujuan untuk mengetahui kualitas website situs Program Studi Sistem Informasi Universitas PGRI Madiun (atau berikutnya disebut Prodi SI UNIPMA) dengan metode Webqual_4.0 yang memiliki 4 variabel yaitu kualitas informasi, kualitas kegunaan, layanan interaksi dan kualitas secara keseluruhan. Populasi pada penelitian ini adalah mahasiswa Prodi SI UNIPMA dimana jumlah sampel diambil sebanyak 21 responden. Analisis Regresi Linear Berganda dipergunakan untuk pengujian hubungan antara variabel dalam Webqual 4.0 terhadap kepuasan mahasiswa. Hasil dari penelitian ini dapat diambil kesimpulan bahwa, diantara variabel yang paling berpengaruh dalam kepuasan adalah kualitas informasi dengan nilai 14,131 dan yang terkecil adalah variabel kualitas kegunaan dengan nilai 2,266. Maka dapat diperoleh rekomendasi untuk website adalah peningkatan dimensi kegunaan website terhadap mahasiswa.
\end{abstract}

Kata Kunci-Webqual 4.0, kualitas website, regresi linear berganda

Abstract - This study aims to determine the quality of the website of the Program Studi Sistem Informasi Universitas PGRI Madiun (or later called Prodi SI UNIPMA) with the Webqual 4.0 method which has 4 variables, namely quality of use, quality of information, interaction services and overall quality. The population in this study were students of SI UNIPMA Study Program where 21 respondents were taken as samples. Multiple linear regression analysis is used to test the relationship between variables Webqual 4.0 and student satisfaction. From the results of this study, it can be concluded that the most influential variable in satisfaction is the quality of information with a value of 14.131 and the smallest is the variable quality of use with a value of 2.266. So the recommendations for the website can be obtained is to increase the dimensions of the website's usefulness to students.

Keywords - Webqual 4.0, website quality, multiple linear regression. 
INTENSIF, Vol.3 No.1 February 2019

ISSN: 2580-409X (Print) / 2549-6824 (Online)

Website: http://ojs.unpkediri.ac.id/index.php/intensif

\section{PENDAHULUAN}

Pertumbuhan Teknologi Informasi dan Komunikasi yang berkembang kian pesat membuat website merupakan bagian dari Perguruan Tinggi yang tidak akan dapat terpisahkan dalam hal layanan untuk pengguna[1]. Penerapan teknologi pada institusi pendidikan sekarang hampir keseluruhnya telah memiliki fasilitas internet dan web yang menjadi salah satu contoh pelayanan informasi kepada mahasiswa, dosen, alumni, karyawan dan bahkan masyarakat umum [2]. Website merupakan salah satu jenis layanan/fasilitas yang disediakan oleh internet yang paling banyak digunakan disamping layanan-layanan yang lainnya[3]. Website wajib mempunyai konten informasi dengan kualitas yang baik dan kenyamanan bagi pengguna awam dalam penggunaannya untuk mendapatkan sebuah informasi yang diperlukan[4]. Dengan adanya hal tersebut, sangat dibutuhkan analisis tentang apa saja faktor yang akan mempengaruhi pada tingkatan kualitas sebuah web[5]. Suatu organisasi atau lembaga yang menggunakan manfaat dari teknologi informasi serta digunakan secara maksimal akan dapat bertahan pada era global saat ini, karena dengan memanfaatkan teknologi informasi suatu organisasi akan dapat mencari informasi yang diinginkan dengan tepat, akurat, dan cepat[6][7].

Kepuasan merupakan upaya dalam pemenuhan sesuatu atau dengan kata lain membuat sesuatu yang memadai. semua akan dapat mengetahui apa itu arti dari kepuasan. Akan tetapi begitu diminta untuk menjelaskannya, terlihat tak seorangpun tahu[8]. Beberapa penelitian terkait analisa web diantaranya dilakukan oleh Julius Jillbert pada tahun 2014 Analisa penilaian Situs web perusahaan kimia terhadap strategi dan kualitas Situs Web dalam upaya untuk mendapatkan ukuran objektif dan subjektif dari kualitas situs web. Analisis konten informasi juga menilai situs web Deza lebih unggul daripada Koppers dan lebih rendah daripada Nalon. [9]. Penelitian lain dilakukan oleh Reza Tehrani dan Hamid Jamshidi pada tahun 2015 bahwa penilaian website dapat meningkatkan tingkat diterima dan berguna untuk perdagangan, pembelian dan penjualan telah menjadi dan perubahan mendasar dalam struktur industri dan perdagangan. Hal tersebut dapat memperkuat loyalitas pelanggan untuk perusahaan yang beroperasi di ruang elektronik sebagai sebuah tantangan strategis dibahas dalam bidang mempertahankan dan mengembangkan posisi kompetitif di ruang virtual[10].

WebQual merupakan metode atau teknik untuk mengukur kualitas website atas dasar persepsi pengguna[11]. Teknik ini tercipta dari pengembangan metode SERVQUAL yang telah banyak digunakan oleh peneliti sebelumnya. Model WebQual terdapat beberapa versi, yang di setiap version telah dipergunakan dalam beberapa penelitian berbeda dan disesuaikan dengan jumlah populasi serta kebutuhan dari penelitian yaitu [12]: 
INTENSIF, Vol.3 No.1 February 2019

ISSN: 2580-409X (Print) / 2549-6824 (Online)

Website: http://ojs.unpkediri.ac.id/index.php/intensif

1. WebQual 1.0 memiliki empat variabel : Interaction, Usefulness, Easy of Use, dan Entertainment.

2. WebQual 2.0 memiliki tiga variabel : Quality of Service Interaction, Quality of Website, dan Quality of Information.

3. WebQual 3.0 memiliki tiga variabel dari kualitas website commerce : Quality of Service Interaction, Usability, dan Information quality.

4. WebQual 4.0 merupakan pengembangan WebQual_1.0 hingga 3.0 serta dikembangkan dan disesuaikan dari metode SERVQUAL. Dalam WebQual _4.0 memiliki 4(empat) variabel yang diantaranya Usability, Service Quality, Information, dan Overall.

\section{METODE PENELITIAN}

Metode pengambilan data dilakukan menggunakan beberapa metode :

1. Metode Observasi

Observasi dilakukan di Prodi SI UNIPMA dengan tujuan menganalisa tingkat kepuasan mahasiswa terhadap Website Program Studi yang sedang berjalan. Waktu observasi selama tahun pelajaran 2016/2017.

2. Metode Wawancara

Metode wawancara dilaksanakan pada pihak-pihak yang merupakan sumber data untuk dapat dijadikan acuan variable mana yang sesuai dengan kebutuhan pengguna. Materi dalam wawancara seputar lingkup bidang akademik, dan beberapa pihak pengguna Website. Pihak yang diambil keterangan diantaranya: Ka Prodi, Dosen Prodi Sistem Informasi, Mahasiswa Prosi Sistem Informasi, alumni serta beberapa pihak stakeholder yang bekerja sama dengan Prodi Sistem Informasi

3. Studi Pustaka atau Literatur

Studi pustaka dalam penelitian ini menggunakan bahan yang berasal dari artikel ilmiah atau jurnal yang berkaitan dengan penelitian, serta literatur dari internet serta media publikasi lain yang dianggap bisa untuk dijadikan sumber data masukan dalam penelitian ini.

\section{Kuisioner}

Kuisioner dibuat untuk melengkapi hasil evaluasi penggunaan Sistem Informasi. Pernyataan pada kuisioner dibuat sesuai dengan standar Webqual 4.0 dengan bahasa yang sederhana agar tidak membingungkan responden saat mengisi kuisioner. Pengukuran kuisioner menggunakan metode Likert's. Kemudian dari data yang diperoleh akan di analisis dengan SPSS ( Software Statistical Product and Service Solution ).

Alat analisis yang dipakai adalah regresi linear. Analisis regresi merupakan salah satu pendekatan analisis yang dapat dipergunakan dalam memberikan definisi hubungan matematis 
INTENSIF, Vol.3 No.1 February 2019

ISSN: 2580-409X (Print) / 2549-6824 (Online)

Website: http://ojs.unpkediri.ac.id/index.php/intensif

pada variabel nilai output atau dependen (y) dengan nilai 1 atau dengan beberapa variabel nilai input atau independen (x). Hubungan matematis diperlukan dalam model regresi yang dapat dipergunakan dalam memprediksi nilai output (y) yang didapatkan dari nilai input (x) tertentu. Dengan adanya analisis regresi, akan dapat diketahui variabel independen mana yang signifikan memengaruhi dari variabel dependen dengan variabel independen yang signifikan tadi akan dapat digunakan dalam memprediksi nilai dari variabel dependen [13]. Software yang akan digunakan adalah SPSS 22. Model statistika linier untuk analisis regresi linier berganda secara umum seperti persamaan berikut :

$$
Y^{\prime}=a+b_{1} x_{1}+b_{2} x_{2}+b_{3} x_{3}+\ldots+b_{n} x_{n}
$$

Keterangan :

$Y^{\prime}$ : Variabel dependen (variabel respon)

a : Nilai konstanta

$b \quad$ : Nilai koefisien regresi

$\mathrm{X} 1$ : Nilai Variabel respon 1

$\mathrm{X} 2$ : Nilai Variabel respon 2

$\mathrm{X} 3$ : Nilai Variabel respon 3

Xn : Nilai Variabel respon ke-n

\section{HASIL DAN PEMBAHASAN}

Pelaksanaan penelitian ini dilakukan dengan teknik/metode survey, yang dalam pengumpulan data primer telah dilakukan dengan menyebarkan pertanyaan (kuesioner). Sampel data didapat dari 21 responden di Prodi SI UNIPMA. Ukuran dari sampel pada survey ini di atas dari sampling yang ada dalam penelitian Vidgen dan Barnes (2001) dengan pengukuran kualitas dari website dengan topik berita. Pada Sampel ini dipilih dengan cara random dari responden mahasiswa dengan metode snowball sebagai penggunaan terbanyak pada website Prodi SI UNIPMA. Tingkat signifikansi telah dipilih yaitu 6\%. Dalam alasan efektivitas, di dalam kuesioner ini tidak akan ditanyakan tentang profil responden terkait pendidikan, usia, dan lain sebagainya, karena hal tersebut memang tidak digunakan didalam analisis penelitian ini. Skala ukur yang dipergunakan pada penelitian ini adalah 4 poin dalam skala Likert.

Pengguna melakukan penilaian dari website Prodi SI UNIPMA tentang bagaimana kualitas website menggunakan skala 4 (sangat tidak setuju), 3(setuju), 2 (tidak setuju), dan 1 (sangat tidak setuju). Diluar Perdebatan tentang apakah dalam skala Likert memiliki jenis data ordinal atau interval, dalam penelitian ini dapat di artikan data yang diperoleh merupakan jenis 
INTENSIF, Vol.3 No.1 February 2019

ISSN: 2580-409X (Print) / 2549-6824 (Online)

Website: http://ojs.unpkediri.ac.id/index.php/intensif

interval, maka dapat digunakan dalam statistika parametrik seperti analisis regresi linier berganda. komponen dari 4(empat) variabel WebQual 4.0. pada gambar 1 [14]

\begin{tabular}{|c|c|}
\hline Quality & Description \\
\hline \multicolumn{2}{|l|}{ Usability } \\
\hline 1 & I find the site easy to learn to operate \\
\hline 2 & My interaction with the site is clear and understandable \\
\hline 3 & I find the site easy to navigate \\
\hline 4 & I find the site easy to use \\
\hline 5 & The site has an attractive appearance \\
\hline 6 & The design is appropriate to the type of site \\
\hline 7 & The site conveys a sense of competency \\
\hline 8 & The site creates a positive experience for me \\
\hline \multicolumn{2}{|c|}{ Information Quality } \\
\hline 9 & Provides accurate information \\
\hline 10 & Provides believable information \\
\hline 11 & Provides timely information \\
\hline 12 & Provides relevant information \\
\hline 13 & Provides easy to understand information \\
\hline 14 & Provides information at the right level of detail \\
\hline 15 & Presents the information in an appropriate format \\
\hline \multicolumn{2}{|c|}{ Interaction Quality } \\
\hline 16 & Has a good reputation \\
\hline 17 & It feels safe to complete transactions \\
\hline 18 & My personal information feels secure \\
\hline 19 & Creates a sense of personalization \\
\hline 20 & Conveys a sense of community \\
\hline 21 & Makes it easy to communicate with the organization \\
\hline 22 & I feel confident that goods/services will be delivered as promised \\
\hline \multicolumn{2}{|c|}{ Overall impression } \\
\hline 23 & My overall view of this Web-site \\
\hline
\end{tabular}

Gambar 1. VARIABEL WEBQUAL 4.0

Uji Reabilitas dan Validitas

1. Pengujian Validitas

Uji Validitas ini dilakukan untuk mengetahui ketidakvalidan dari item-item pertanyaan yang diberikan. metode ini digunakan dengan cara membandingkan nilai dari hasil kuesioner pada tingkat kepentingan serta tingkat kepuasan yang ada pada nilai Corrected Item-Total dengan nilai dari $r$ tabel. Nilai dari $r$ tabel dengan tingkat signifikansi 0,06 dari jumlah data $=21$, maka akan didapatkan $r$ tabel sebesar 0,344. Dari analisis ini akan dapat terlihat bahwa semua item telah memiliki nilai corrected item total di atas 0,344 sehingga pada semua variabel dengan tingkat kepentingan dapat dinyatakan valid 
INTENSIF, Vol.3 No.1 February 2019

ISSN: 2580-409X (Print) / 2549-6824 (Online)

Website: http://ojs.unpkediri.ac.id/index.php/intensif

\section{Pengujian Realibilitas}

Hasil output SPSS 22 dapat dilihat dari tabel 2 bahwa nilai dari cronbach alpha ditunjukkan dengan angka berada di atas nilai cronbach alpha minimum yaitu 0,70 maka diperoleh pernyataan bahwa untuk semua pertanyaan uji kepuasan sudah reliabel.

Tabel 1. HASIL DARI PENGUJIAN REABILITAS

\begin{tabular}{ll}
\hline \hline Reliability Statistics & \\
\hline Cronbach's Alpha & N of Items \\
\hline .828 & 27 \\
\hline
\end{tabular}

3. Hasil Analisis dengan Statistik Kuantitatif

\section{Pengujian Korelasi}

Pengujian korelasi ini digunakan dalam mencari keeratan hubungan antara kepuasan dari mahasiswa terhadap website Prodi SI UNIPMA. Hipotesis dalam uji korelasi adalah sebagai berikut:

a. $\mathrm{H}_{0}$ ditolak apabila nilai $\operatorname{Sig}_{\text {hit }} \leq \operatorname{Sig}_{\text {prob }}$ atau $r_{\text {hitung }} \geq \mathrm{r}_{\text {tabel, }}$ ada hubungan kepuasan dari mahasiswa terhadap website Prodi SI UNIPMA.

b. $\mathrm{H}_{0}$ diterima apabila nilai $S i g_{h i t}>S i g_{\text {prob }}$ atau $\mathrm{r}_{\text {hitung }}<\mathrm{r}_{\text {tabel, }}$ tidak ada hubungan kepuasan dari mahasiswa terhadap website Prodi SI UNIPMA.

Untuk uji korelasi antara kepuasan mahasiswa terhadap website Prodi SI UNIPMA, yang diolah dengan SPSS for windows v22.0, dengan hasil sebagaimana tabel 2.:

Tabel 2. HASIL PENGUJIAN KORELASI

\begin{tabular}{lcccc}
\hline \hline \multicolumn{5}{c}{ Model Summary } \\
\hline Model & $R$ & $R$ Square & Adjusted R Square & Std. Error of the Estimate \\
\hline 1 & $.999^{\mathrm{a}}$ & .998 & .998 & .462 \\
\hline a. & Predictors: (Constant), Overal_x4, Information_x2, Usabilitu_x1, Interaction_x3 \\
\hline
\end{tabular}

Berdasarkan tabel 3, dapat dikatakan nilai $r_{\text {hitung }}$ sebesar 0,999 sedangkan $r_{\text {tabel }} 0,344$. Dilain

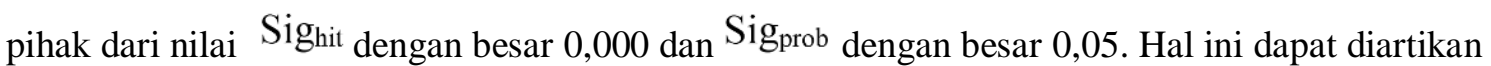
nilai $r_{\text {hitung }} \geq r_{\text {tabel }}(0,999 \geq 0,344)$ atau $\operatorname{Sig}_{\text {hit }} \leq \operatorname{Sig}_{\text {prob }}(0,000 \leq 0,06)$. Didapat kesimpulan bahwa ada hubungan antara kepuasan dari mahasiswa terhadap website Prodi SI UNIPMA. Sedangkan bila dilihat dari nilai sumbangan sistem informasi terhadap kepuasan mahasiswa yang dilihat dari besarnya $\mathrm{R}^{2}$ atau $\mathrm{R}$ Square. dengan besar 0,998 . Hal ini dapat diartikan bahwa nilai sumbangan sistem informasi terhadap kepuasan mahasiswa sebesar $99.80 \%$, sedangkan yang 0,20 dipengaruhi oleh nilai faktor lain. 
INTENSIF, Vol.3 No.1 February 2019

ISSN: 2580-409X (Print) / 2549-6824 (Online)

Website: http://ojs.unpkediri.ac.id/index.php/intensif

\section{Uji Keseluruhan/Uji Fisher}

Uji Fisher dipergunakan dalam mencari pengaruh kepuasan dari mahasiswa terhadap website Prodi SI UNIPMA. Hipotesis dari uji Fisher yang dipergunakan adalah sebagai berikut:

a. $\mathrm{H}_{0}$ ditolak apabila nilai $\mathrm{F}_{\text {hitung }} \geq \mathrm{F}_{\text {tabel }}$ atau $\mathrm{Sig}_{\text {hit }} \leq \mathrm{Sig}_{\text {prob }}$ berarti terdapat pengaruh kepuasan dari mahasiswa terhadap website Prodi SI UNIPMA.

b. $\mathrm{H}_{0}$ diterima apabila nilai $\mathrm{F}_{\text {hitung }}<\mathrm{F}_{\text {tabel }}$ atau $\mathrm{Sig}_{\text {hit }} \leq \mathrm{Sig}_{\text {prob }}$ berarti tidak ada pengaruh pengaruh kepuasan dari mahasiswa terhadap website Prodi SI UNIPMA.

hasil dari perhitungan uji Fisher tertera pada tabel 3.:

Tabel 3. HASIL UJI FISHER

\begin{tabular}{|c|c|c|c|c|c|c|}
\hline \multicolumn{7}{|c|}{ ANOVA $^{b}$} \\
\hline Model & & Sum of Squares & df & Mean Square & $\mathrm{F}$ & Sig. \\
\hline \multirow[t]{3}{*}{1} & Regression & 3.619 .902 & 4 & 904.975 & $4,24 \mathrm{E}+06$ & $.000^{\mathrm{a}}$ \\
\hline & Residual & 5.977 & 28 & .213 & & \\
\hline & Total & 3.625 .879 & 32 & & & \\
\hline \multicolumn{7}{|c|}{ a. $\quad$ Predictors: (Constant), Overal_x4, Information_x2, Usabilitu_x1, Interaction_x3 } \\
\hline \multicolumn{7}{|c|}{ b. Dependent Variable: $Y$} \\
\hline
\end{tabular}

Analisa pada tabel 3 dapat diketahui nilai $F_{\text {hitung }}$ sebesar 4.240E3 sedangkan nilai $F_{\text {tabel }}$

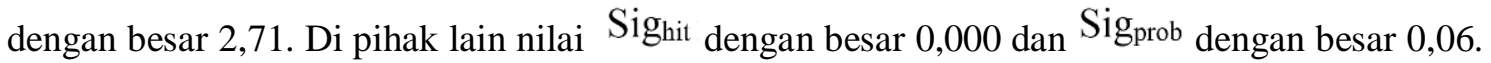
Hal ini dapat di artikan bahwa nilai $F_{\text {hitung }} \geq F_{\text {tabel }}(4.240 \mathrm{E} 3 \geq 2,71) \quad \operatorname{Sig}_{\text {hit }} \leq \operatorname{Sig}_{\text {prob }}(0,000 \leq$ 0,06). Hal tersebut dapat disimpulkan bahwa $\mathrm{H}_{0}$ ditolak, dengan pengertian ada pengaruh kepuasan dari mahasiswa terhadap website Prodi SI UNIPMA.

\section{Uji t (Uji Koefisien Regresi)}

Uji Koefisien Regresi diperlukan agar dapat mengetahui beda pengaruh antara kepuasan dari mahasiswa terhadap Website Prodi SI UNIPMA. Hipotesis yang dipergunakan dalam Uji Koefisien adalah :

a. $\mathrm{H}_{0}$ ditolak apabila nilai $\mathrm{t}_{\text {hitung }} \geq \mathrm{t}_{\text {tabel }}$ atau $\mathrm{Sig}_{\text {hit }} \leq \mathrm{Sig}_{\text {prob }}$ berarti ada beda pengaruh kepuasan dari mahasiswa terhadap website Prodi SI UNIPMA.

b. $\mathrm{H}_{0}$ diterima apabila nilai $\mathrm{t}_{\text {hitung }}<\mathrm{t}_{\text {tabel }}$ atau $\mathrm{Sig}_{\text {hit }} \leq \mathrm{Sig}_{\text {prob }}$ dapat diartikan tidak ada beda pengaruh kepuasan dari mahasiswa terhadap website Prodi SI UNIPMA. 
INTENSIF, Vol.3 No.1 February 2019

ISSN: 2580-409X (Print) / 2549-6824 (Online)

Website: http://ojs.unpkediri.ac.id/index.php/intensif

Tabel 4. HASIL DARI KOEFISIEN REGRESI (UJI T)

\begin{tabular}{|c|c|c|c|c|c|c|}
\hline \multicolumn{7}{|c|}{ Coefficients $^{a}$} \\
\hline & \multirow[t]{2}{*}{ Model } & \multicolumn{2}{|c|}{$\begin{array}{l}\text { Unstandardized } \\
\text { Coefficients }\end{array}$} & \multirow{2}{*}{$\begin{array}{c}\text { Standardized } \\
\text { Coefficients }\end{array}$} & \multirow[t]{2}{*}{$\mathrm{t}$} & \multirow[t]{2}{*}{ Sig. } \\
\hline & & B & Std. Error & & & \\
\hline \multirow{5}{*}{1} & (Constant) & .476 & .495 & & .960 & .345 \\
\hline & Usability_xl & .193 & .085 & .088 & 2.266 & .031 \\
\hline & Information_x2 & .929 & .066 & .317 & 14.131 & .000 \\
\hline & Interaction_x3 & 1.272 & .109 & .465 & 11.719 & .000 \\
\hline & Overal_x4 & .719 & .100 & .163 & 7.192 & .000 \\
\hline & pendent Varial & & & & & \\
\hline
\end{tabular}

Analisa diperoleh dalam uji t tabel 4. dalam uji $t$ atau koefisien regresi diperoleh nilai $t_{\text {hitung }}$ untuk :

Nilai $t_{\text {hitung }}$ untuk $X_{1}$ atau usability sebesar 2,266 sedangkan $t_{\text {tabel }}$ dengan Dk sebesar 32 adalah 2,037 dengan nilai $\mathrm{Sig}_{\text {hit }}$ dengan besar $0,000 \leq$ Sig $_{\text {prob }}$ sebesar 0,06 . Hal ini dapat diartikan nilai $t_{\text {hitung }} \geq t_{\text {tabel }}(2,266 \geq 2,037)$ atau $\operatorname{Sig}_{\text {hit }} \leq \operatorname{Sig}_{\text {prob }}(0,000 \leq 0,031)$. Dari hasil uji Koefisien tersebut dapat dikatakan bahwa $\mathrm{H}_{0}$ ditolak artinya terdapat beda pengaruh kepuasan mahasiswa dalam usability terhadap website Prodi SI UNIPMA.

Nilai $t_{\text {hitung }}$ untuk $\mathrm{X}_{2}$ atau Information sebesar 14,131 sedangkan $\mathrm{t}_{\text {tabel }}$ dengan Dk

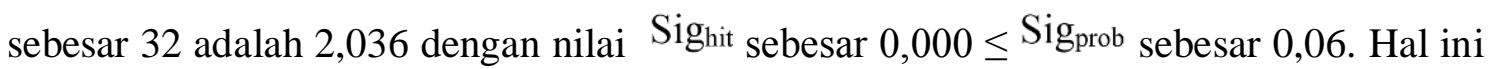
dapat diartikan nilai $t_{\text {hitung }} \geq \mathrm{t}_{\text {tabel }}(14,131 \geq 2,036)$ atau $\operatorname{Sig}_{\text {hit }} \leq \operatorname{Sig}_{\text {prob }}(0,000 \leq 0,031)$. Dari hasil uji Koefisien tersebut bisa dikatakan bahwa $\mathrm{H}_{0}$ ditolak artinya terdapat beda pengaruh kepuasan mahasiswa dalam information terhadap website Prodi SI UNIPMA.

Nilai $t_{\text {hitung }}$ untuk $\mathrm{X}_{3}$ atau Interaction sebesar 11,719 sedangkan $\mathrm{t}_{\text {tabel }}$ dengan Dk sebesar 32 adalah 2,037dengan nilai Sighit $_{\text {sebesar } 0,000 \leq} \leq$ Sig $_{\text {prob }}$ sebesar 0,06. Hal ini berarti nilai $t_{\text {hitung }}$ $\geq \mathrm{t}_{\text {tabel }}(11,719 \geq 2,036)$ atau $\operatorname{Sig}_{\text {hit }} \leq \operatorname{Sig}_{\text {prob }}(0,000 \leq 0,031)$. Dari hasil uji Koefisien tersebut bisa dikatakan bahwa $\mathrm{H}_{0}$ ditolak artinya terdapat beda pengaruh kepuasan mahasiswa dalam interaction terhadap website Prodi SI UNIPMA. Nilai $t_{\text {hitung }}$ untuk $\mathrm{X}_{4}$ atau overall impression sebesar 7,192 sedangkan $t_{\text {tabel }}$ dengan Dk sebesar 32 adalah 2,036dengan nilai Sighit sebesar $0,000 \leq$ Sig $_{\text {prob }}$ sebesar 0,05 . Hal ini dapat diartikan nilai $t_{\text {hitung }} \geq t_{\text {tabel }}(7,192 \geq 2,036)$ atau $\operatorname{Sig}_{\text {hit }} \leq \operatorname{Sig}_{\text {prob }}(0,000 \leq 0,031)$. Dari hasil uji t tersebut dapat dikatakan bahwa $\mathrm{H}_{0}$ ditolak artinya terdapat beda pengaruh kepuasan mahasiswa dalam overal impression terhadap website Prodi SI UNIPMA. 
INTENSIF, Vol.3 No.1 February 2019

ISSN: 2580-409X (Print) / 2549-6824 (Online)

Website: http://ojs.unpkediri.ac.id/index.php/intensif

Lebih detail lagi jika dilihat dari persamaan regresi dihasilkan persamaan nilai

$$
\mathrm{Y}=0,476+0,193 \mathrm{X}_{1}+0,929 \mathrm{X}_{2}+1,272 \mathrm{X}_{3}+0,719 \mathrm{X}_{4}
$$

Dari hasil persamaan garis regresi tersebut, maka bisa dikatakan :

1. Jika kepuasan dalam Usability meningkat sebesar $1 \%$, kualitas website Prodi SI UNIPMA akan naik dengan nilai $0,1931 \%$, apabila faktor yang lainnya dianggap konstan.

2. Jika kepuasan dalam Information meningkat sebesar 1\%, kualitas website Prodi SI UNIPMA naik dengan nilai 0,929\%, apabila faktor yang lainnya dianggap konstan.

3. Jika kepuasan dalam Interaction meningkat sebesar $1 \%$, kualitas website Prodi SI UNIPMA naik dengan nilai 1,272\%, apabila faktor yang lainnya dianggap konstan.

Jika kepuasan dalam overall Impression meningkat sebanyak 1\%, kualitas website Prodi SI UNIPMA akan naik dengan nilai 0,719\%, apabila faktor yang lainnya dianggap konstan.

Atas hasil analisis data ternyata ternyata $F_{\text {hit }}$ diperoleh sebesar 4.240E3, sedangkan $F_{\text {tab }}$ dengan taraf kepercayaan 95\% dengan $\mathrm{Df}=4$ dan 28 diperoleh nilai $4.240 \mathrm{E} 3$ hal ini berarti $\mathrm{F}_{\text {hit }}>\mathrm{F}_{\text {tab }}$. (4.240E3 > 2,76). Oleh karena $\mathrm{F}_{\text {hit }}>\mathrm{F}_{\mathrm{tab}}$, yang berarti $\mathrm{H}_{\mathrm{o}}$ ditolak dan Ha diterima, keadaan ini dapat dinyatakan "Ada pengaruh kepuasan mahasiswa terhadap kualitas website Prodi SI UNIPMA.

Adanya pengaruh ini ini disebabkan : bahwa kualitas website berpengaruh signifikan pada Kepuasan Mahasiswa. Ini berarti bahwa semakin baik kualitas website yang diberikan oleh website Prodi SI UNIPMA pada mahasiswa maka akan meningkatkan citra lembaga di mata mahasiswa. Kualitas website Prodi SI UNIPMA tersebut meliputi kemudahan penggunaan website, kualitas informasi, dan kualitas interaksi website terhadap mahasiswa. Atas dasar analisis data diperoleh hasil $\mathrm{F}_{\text {hit }}$ sebesar 4.240E3, sedangkan $\mathrm{F}_{\text {tab }}$ dengan taraf kepercayaan $95 \%$ dengan $\mathrm{Df}=4$ dan 28 diperoleh nilai 4.240E3 hal ini berarti $\mathrm{F}_{\text {hit }}>\mathrm{F}_{\text {tab }}$. (4.240E3 > 2,76). Oleh karena $F_{\text {hit }}>F_{\text {tab }}$ berarti $H_{o}$ ditolak dan $H_{a}$ diterima, artinya "Ada pengaruh pengaruh kepuasan mahasiswa terhadap kualitas website Prodi SI UNIPMA", hal ini berarti bahwa hipotesis yang telah diajukan diterima.

\section{KESIMPULAN DAN SARAN}

Hasil analisis kepuasan mahasiswa terhadap kualitas website Prodi SI UNIPMA dengan menggunakan metode WebQual diperoleh bahwa variabel yang paling mempengaruhi dalam kepuasan adalah Information Quality dengan besar nilai 14,131. Dibawah Information Quality ada interaction Quality dengan besar nilai 11,719. Selanjutnya Overall Impression dengan nilai 7,192 dan yang terkecil Usability dengan nilai 2.266. Dilihat dari nilai yang terkecil adalah variabel Usability, maka dapat diperoleh rekomendasi untuk website Prodi SI UNIPMA peningkatan Usability atau dimensi kegunaan Sistem Informasi terhadap mahasiswa. 
INTENSIF, Vol.3 No.1 February 2019

ISSN: 2580-409X (Print) / 2549-6824 (Online)

Website: http://ojs.unpkediri.ac.id/index.php/intensif

\section{DAFTAR PUSTAKA}

[1] I. Sanjaya, "PENGUKURAN KUALITAS LAYANAN WEBSITE KEMENTERIAN KOMINFO DENGAN MENGGUNAKAN METODE WEBQUAL 4.0 MINISTRY OF COMMUNICATION AND INFORMATION WEBSITE QUALITY MEASUREMENT BASED ON WEBQUAL 4.0 METHOD,”J. Penelit. IPTEK-KOM, vol. 14, no. 1, 2012.

[2] Y. Prasetyo dan D. O. Siahaan, Prosiding Seminar Nasional Manajemen Teknologi XVI Program Studi MMT-ITS. 2012.

[3] A. W. Soejono, A. Setyanto, dan A. F. Sofyan, "Evaluasi Usability Website UNRIYO Menggunakan System Usability Scale (Studi Kasus: Website UNRIYO),” J. Teknol. Inf. Respati, vol. 13, no. 1, Mar 2018.

[4] R. Pamungkas, Teori dan Implementasi Pemrograman WEB, 1 ed., no. 1. Madiun: Unipma Press, 2018.

[5] G. P. Utama, A. Hamzah, dan U. Lestari, "SISTEM PENGUJIAN KUALITAS WEBSITE MENGGUNAKAN METODE WEBQUAL 4.0 (STUDI KASUS PADA PORTAL SISTEM INFORMASI AKADEMIK DI INSTITUT SAINS \&amp; TEKNOLOGI AKPRIND YOGYAKARTA)," J. Scr., vol. 4, no. 2, Nov 2017.

[6] R. Pamungkas, "Perancangan Sistem Informasi Pembayaran Administrasi SMK Negeri 1 Jiwan," INTENSIF, vol. 1, no. 2, hal. 129, Agu 2017.

[7] Sucipto, S., \& Karaman, J. (2015). Perancangan Sistem Informasi Strategis Balai Desa Gadungan Untuk Integrasi Sistem Informasi Publikasi. In Seminar Nasional Teknologi Informasi dan Multimedia 2015 (p. 2.3-31-2.3-36). Yogyakarta: STMIK AMIKOM Yogyakarta.

[8] W. Abbas, ANALISA KEPUASAN MAHASISWA TERHADAP WEBSITE UNIVERSITAS NEGERI YOGYAKARTA (UNY), vol. 6. 2015.

[9] Jillbert, J. (2014). Subjective and objective measurement of websites quality in a chemical industry. Journal of Systems Integration, 5(4), 9-18.

[10] Tehrani, R., \& Jamshidi, H. (2015). Analysis of the Impact Factors Information Quality, System Quality, Interface Design Quality on Customer Loyalty System Websites According to the Role

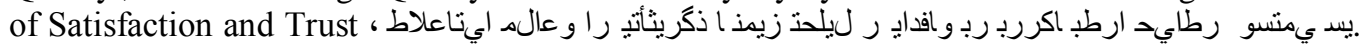
Iranian Journal of Information Processing \& Management, 30(4), 1085-1106.

[11]N. Q. Nada dan S. Wibowo2, "Pengukuran Kualitas Layanan Sistem Informasi Akademik Menggunakan Metode Webqual 4.0,” J. Inform. Upgris, vol. 1, no. 2 Desember, 2015.

[12] Y. Pratama dan D. S. Kusumo, "Pengukuran Kualitas Website CDC Universitas Telkom Menggunakan Metode WebQual 4.0,” eProceedings Eng., vol. 2, no. 1, Apr 2015.

[13] A. E. Wibowo, Aplikasi Praktis SPSS dalam Penelitian. Yoyakarta: Gava Media, 2012.

[14] S. J. Barnes dan R. T. Vidgen, "Barnes \&amp; Vidgen: An Integrative Approach to the Assessment of E-Commerce Quality AN INTEGRATIVE APPROACH TO THE ASSESSMENT OF E-COMMERCE QUALITY." 